\title{
A Narrative Pharmacological Review of Buprenorphine: A Unique Opioid for the Treatment of Chronic Pain
}

Jeffrey Gudin · Jeffrey Fudin

Received: November 18, 2019 / Published online: January 28, 2020

(C) The Author(s) 2020

\section{ABSTRACT}

Buprenorphine is a Schedule III opioid analgesic with unique pharmacodynamic and pharmacokinetic properties that may be preferable to those of Schedule II full $\mu$-opioid receptor agonists. The structure of buprenorphine allows for multimechanistic interactions with opioid receptors $\mu, \delta, \kappa$, and opioid receptor-like 1 . Buprenorphine is considered a partial agonist

Enhanced Digital Features To view enhanced digital features for this article go to https://doi.org/10.6084/ m9.figshare.11353028.

J. Gudin ( $\triangle)$

Department of Anesthesiology, Englewood Hospital and Medical Center, 350 Engle St, Englewood, NJ 07631, USA

e-mail: healthmd@optonline.net

J. Gudin

Department of Anesthesia and Perioperative Care, Rutgers New Jersey Medical School, 185 S Orange Ave, Newark, NJ 07103, USA

J. Fudin

Western New England University College of Pharmacy and Health Sciences, 1215 Wilbraham Road, Springfield, MA 01119, USA

J. Fudin

Albany College of Pharmacy \& Health Sciences, 106

New Scotland Avenue, Albany, NY 12208, USA

J. Fudin

Remitigate, LLC, 357 Delaware Avenue \#214,

Delmar, NY 12054, USA with very high binding affinity for the $\mu$-opioid receptor, an antagonist with high binding affinity for the $\delta$ - and $\kappa$-opioid receptors, and an agonist with low binding affinity for the opioid receptorlike 1 receptor. Partial agonism at the $\mu$-opioid receptor does not provide partial analgesia, but rather analgesia equivalent to that of full $\mu$-opioid receptor agonists. In addition, unlike full $\mu$-opioid receptor agonists, buprenorphine may have a unique role in mediating analgesic signaling at spinal opioid receptors while having less of an effect on brain receptors, potentially limiting classic opioid-related adverse events such as euphoria, addiction, or respiratory depression. The pharmacokinetic properties of buprenorphine are also advantageous in a clinical setting, where metabolic and excretory pathways allow for use in patients requiring concomitant medications, the elderly, and those with renal or hepatic impairment. The unique pharmacodynamic and pharmacokinetic properties of buprenorphine translate to an effective analgesic with a potentially favorable safety profile compared with that of full $\mu$-opioid receptor agonists for the treatment of chronic pain.

\section{PLAIN LANGUAGE SUMMARY}

The unique pharmacodynamic and pharmacokinetic properties of the Schedule III opioid 
buprenorphine contribute to its effective pain relief and a potentially favorable safety profile for chronic pain management.

Keywords: Buprenorphine; Chronic pain; Opioid receptor; Pharmacodynamics; Pharmacokinetics; Pharmacology

\section{Key Summary Points}

Given the current state of the opioid crisis, treatment options other than Schedule II full $\mu$-opioid receptor agonists are needed for chronic pain management.

Buprenorphine, a Schedule III opioid, is a partial agonist with very high binding affinity for the $\mu$-opioid receptor, an antagonist with high binding affinity for the $\delta$ - and $\kappa$-opioid receptors, and an agonist with low binding affinity for the opioid receptor-like 1 receptor, allowing for potent analgesia with potential tolerability and safety advantages compared with full $\mu$-opioid receptor agonists.

Buprenorphine may have more of an impact at spinal opioid receptors compared with brain receptors, potentially limiting classic opioid-related adverse events such as euphoria, addiction, or respiratory depression.

The metabolic and excretory pathways associated with buprenorphine allow for use in patients requiring concomitant medications, the elderly, and those with renal or hepatic impairment.

Buprenorphine has unique pharmacological properties that may translate to a more favorable treatment option for chronic pain.

\section{INTRODUCTION}

The misuse and abuse of opioids is a serious crisis faced by the United States that is impacting social and economic welfare and public health $[1,2]$. In recent years in the United States, approximately 11 million people per year have misused prescription pain relievers, the most common being products containing the Schedule II full $\mu$-opioid receptor agonists hydrocodone and oxycodone [3]. Approximately 2 million of these people were considered to have an opioid use disorder, with 1.7 million of these people misusing prescription pain relievers $[2,3]$. More than half of all opioid users took, bought, or were given pain relievers from a friend or relative [3]. The economic burden of opioid misuse is immense, with the Centers for Disease Control and Prevention estimating that $\$ 78.5$ billion a year is spent on lost productivity, healthcare, addiction treatment, and criminal justice involvement [2]. In 2018, it was estimated that more than 130 people were dying each day from prescription and non-prescription opioid overdoses in the United States [2].

In response to the opioid crisis, the US Department of Health and Human Services established a Pain Management Best Practices Inter-Agency Task Force to promote better practices for pain management $[1,2]$. One agreed-upon approach to improving the management of pain is the preferential use of potentially safer analgesics. The task force noted that although buprenorphine is widely used for treating patients with opioid-use disorder, it is also effective and approved for the treatment of pain [4]. The task force also encourages the primary use of buprenorphine, if clinically indicated, rather than only implementing the drug after failure of other opioids such as hydrocodone or fentanyl [4].

The objective of this review is to elaborate on how the unique pharmacological properties of buprenorphine, a Schedule III opioid, may translate to a more favorable treatment option for chronic pain with effective analgesia comparable to that of full $\mu$-opioid receptor agonists, which have higher abuse potential by Drug 
Enforcement Administration (DEA) Schedule definition.

\section{METHODS}

A PubMed search was performed on March 21, 2019, using the MeSH terms "buprenorphine" AND "chronic pain." The specific terms "AND pharmacodynamics," "AND pharmacokinetics," and "AND clinical effects" were then used to identify articles relevant to this review. All articles that present information regarding the biological effects of buprenorphine were included. Additional references were added at the authors' discretion. Both authors take complete responsibility for the integrity of the data and accuracy of the data analysis. This article is based on previously conducted studies and does not contain any studies with human participants or animals performed by either of the authors.

\section{DISCUSSION}

\section{Pharmacodynamics of Buprenorphine}

Buprenorphine is considered a partial $\mu$-opioid receptor agonist with pharmacodynamic properties that result from its unique structure, receptor binding, and downstream receptor signaling events. It is a complex lipophilic molecule derived from the opium alkaloid thebaine of the poppy Papaver somniferum and is composed of multiple chiral centers, a morphine skeleton, and a unique cyclopropylmethyl group [5-7].

In vitro and preclinical studies have shown that buprenorphine exhibits receptor-binding properties that are distinct from those of other opioids, and these observations have led to misconceptions regarding its analgesic potency [8-10]. The unique pharmacological properties of buprenorphine allow for potent analgesia while reducing the intensity of several classic opioid-related adverse events such as respiratory depression and abuse liability, in contrast to the full $\mu$-opioid receptor agonists oxycodone, morphine, and fentanyl, among others [11].
The therapeutic effects of buprenorphine are mediated through interactions with four different opioid receptors $(\mu, \delta, \kappa$, and opioid receptor-like 1 [ORL1]), which are distributed throughout many tissues in the body [12]. Binding affinity describes the ability of a drug to bind to a receptor and is measured by determining the equilibrium dissociation constant $\left(K_{\mathrm{i}}\right)$ [13]. The structure and unique binding position of buprenorphine allow for more molecular interactions between the molecule and $\mu$-opioid receptor, yielding a very high binding affinity (a low $K_{\mathrm{i}}$ value) compared with that of other opioids (Fig. 1) [14-17]. Unlike conventional opioids, buprenorphine is also an antagonist with a high binding affinity at the $\delta$ and $\kappa$-opioid receptors (although some studies have found that buprenorphine is an inverse agonist at the $\kappa$-opioid receptor) and an agonist with lower binding affinity for ORL1, demonstrating its multimechanistic effects on receptor activity $[19,20]$.

Although high binding affinity at the $\mu$-opioid receptor may contribute to receptor occupation by buprenorphine, high binding affinity alone does not correspond to superior receptor activity [13]. In addition to receptor binding and dissociation, individual molecule selectivity, potency, and intrinsic efficacy contribute to individual opioid pharmacodynamic profiles [21]. Buprenorphine exhibits slower dissociation from the $\mu$-opioid receptor compared with other opioids, which may contribute to prolonged analgesia and less potential for withdrawal when used appropriately for chronic pain $[5,17,22]$.

When high doses of buprenorphine are given, its high binding affinity at the $\mu$-opioid receptor and biphasic distribution may result in less receptor availability if additional full $\mu$ opioid receptor agonist opioids are administered [23]. From a safety standpoint, this may lessen the risk of an accidental opioid overdose. As such, concomitant treatment with buprenorphine prior to an opioid overdose is associated with substantial reductions in opioid-related mortality [24]. Buprenorphine occupies a majority but not all $\mu$-opioid receptors; many clinicians are surprised to learn that some receptors remain available for full agonists 


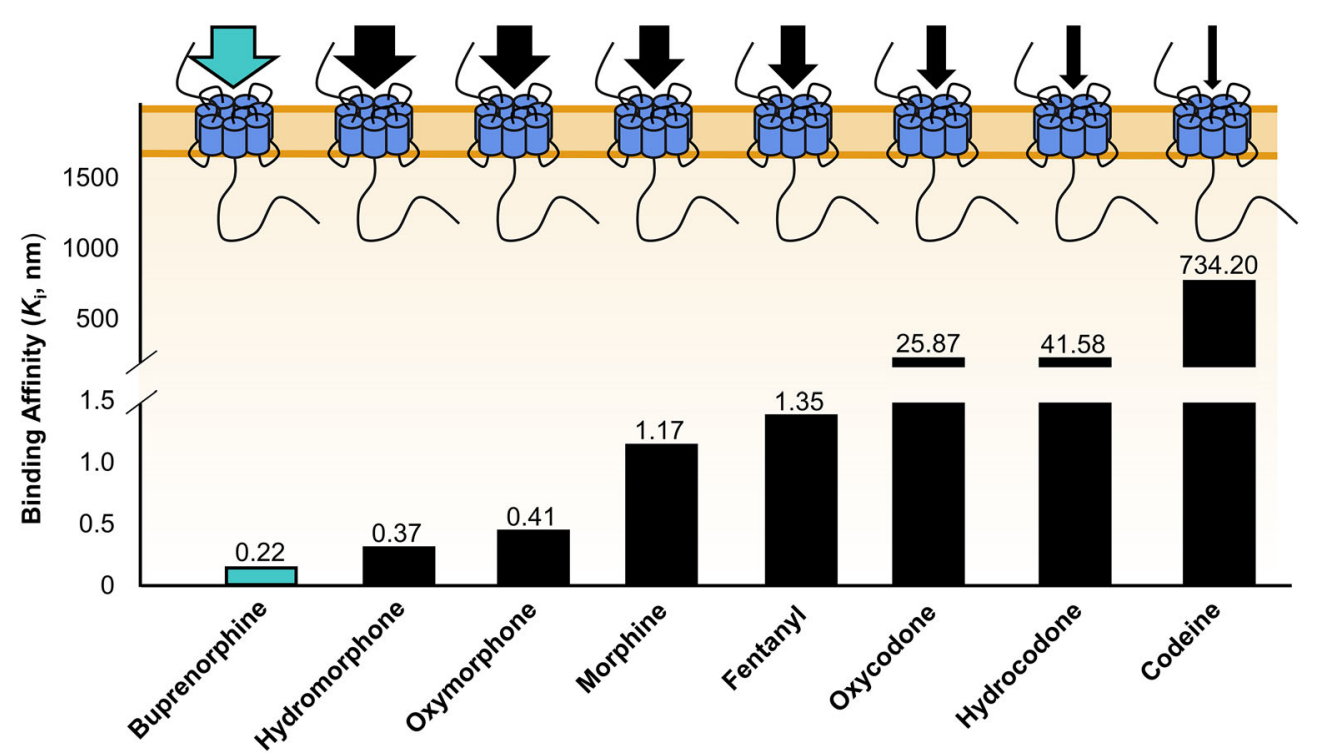

Fig. 1 Buprenorphine exhibits a higher binding affinity at the $\mu$-opioid receptor than full $\mu$-opioid receptor agonists. A low $K_{\mathrm{i}}$ value corresponds to greater binding affinity but does not necessarily translate to greater receptor activity [18]

to bind to if the need arises to treat acute pain [16]. When such full $\mu$-opioid receptor agonists are necessary, those with high lipophilicity and binding affinity may have the best potential for competing against buprenorphine for unoccupied receptors $[25,26]$.

Opioids function pre-synaptically by binding to opioid receptors on cell membranes. Opioid receptors are G-protein receptors that are coupled to guanine nucleotide-binding proteins, known as G-protein subunits (i.e., $\alpha, \beta$, and $\gamma$ ) [12]. The binding of an opioid to the $\mu$-opioid receptor causes receptor phosphorylation, which promotes the release of G-protein subunits, inhibition of adenylyl cyclase, reduction of intracellular cyclic adenosine monophosphate (cAMP) levels, and regulation of ion channels $[12,27]$. These signaling events limit neurotransmitter release and result in hyperpolarization of the cell membrane, thereby preventing nociceptor activation and affording analgesia $[12,27]$. Conversely, phosphorylation at specific amino acid residues on the receptor's cytoplasmic domain may lead to $\beta$-arrestin (an adaptor protein that regulates receptor function and signal transduction activity) recruitment, endocytosis-mediated receptor internalization, and downregulation of $\mu$-opioid receptor signaling $[12,28-32]$. $\beta$-arrestin signaling has also been correlated with respiratory depression, constipation, and abuse liability [12, 33]. G-protein-coupled receptor (GPCR) ligands exhibit functional selectivity, meaning that preferential signaling can occur through different pathways [29, 34, 35]. For example, GPCR ligands can selectively activate different intracellular G-protein signaling pathways, recruit $\beta$ arrestin, or both to varying degrees [29, 34]. Buprenorphine is unique in that it stimulates sufficient G-protein signaling while limiting $\beta$ arrestin recruitment to the receptor $[12,17,33]$. The balance between G-protein and $\beta$-arrestin signaling may determine the extent of analgesia versus the adverse effects commonly observed with opioids (Fig. 2) [12].

In vitro studies have shown that buprenorphine-dependent $\mu$-opioid receptor activation results in lower phosphorylation levels compared with full $\mu$-opioid receptor agonists $[28,36]$. Buprenorphine exhibits substantial phosphorylation of the $\mu$-opioid receptor at one amino acid, serine 375 , whereas other opioids such as DAMGO, etorphine, fentanyl, and sufentanil induce substantial phosphorylation at additional amino acids, namely threonine 370,376 , and 379 [28, 36, 37]. The lack of threonine phosphorylation with buprenorphine may limit $\beta$-arrestin recruitment to the 


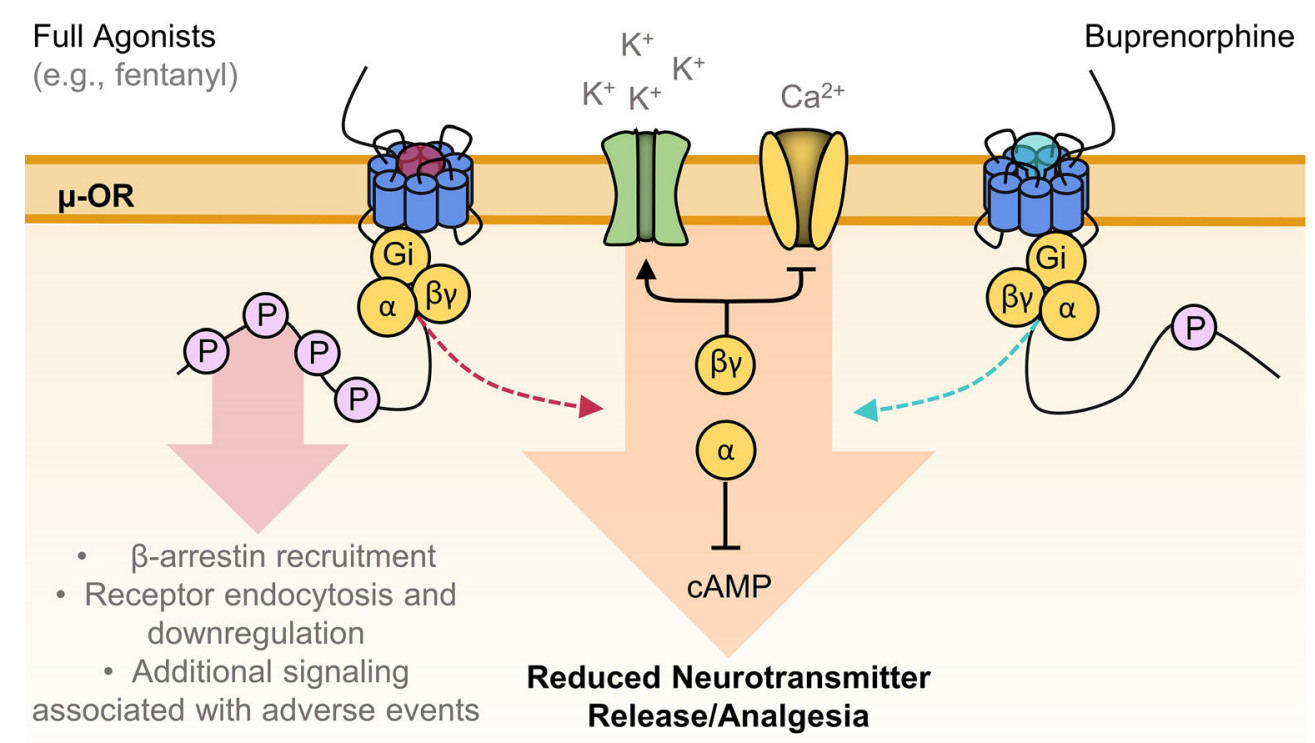

Fig. 2 Buprenorphine promotes analgesia and limits side effects through unique downstream signaling events at the $\mu$-opioid receptor. Activation of the $\mu$-opioid receptor by full agonists (e.g., fentanyl) or a partial agonist such as buprenorphine results in G-protein signaling, which promotes the dissociation of the $\mathrm{G}_{\alpha}$ and $\mathrm{G}_{\beta \gamma}$ subunits $[12,27]$. The $\mathrm{G}_{\beta \gamma}$ subunit inhibits the opening of voltagegated calcium channels and activates G-protein-gated potassium channels, whereas the $G_{\alpha}$ subunit suppresses cAMP levels $[12,27]$. These signaling events lead to reduced neurotransmitter release and membrane hyperpolarization, thereby resulting in analgesia $[12,27]$. Full

receptor and subsequent endocytosis, which could contribute to buprenorphine's potentially favorable safety profile $[12,17,28,36,38]$. Buprenorphine also demonstrates a ceiling effect on serine 375 phosphorylation, whereas full $\mu$-opioid receptor agonists show continuously elevated phosphorylation levels with increasing doses, consistent with the known dose ceiling effect of buprenorphine on respiratory depression $[36,37,39,40]$. This unique $\mu$ opioid receptor activation profile, which results in its partial agonist activity, is likely due to buprenorphine's unique structural binding and therefore differs from that of full $\mu$-opioid receptor agonists.

Although total G-protein signaling from the $\mu$-opioid receptor is lower when activated by agonist opioids cause substantial phosphorylation on multiple amino acid residues on the receptor's carboxylterminal cytoplasmic domain, leading to $\beta$-arrestin recruitment and the endocytosis-mediated downregulation of analgesic signaling $[28,36,37]$. In addition, $\beta$-arrestin signaling has been correlated with adverse events $[12,33]$. Buprenorphine-mediated activation of the $\mu$-opioid receptor is unique in that it limits phosphorylation of the receptor and $\beta$-arrestin recruitment $[12,17,33] . \mathrm{Ca}^{2+}$ calcium ion, $c A M P$ cyclic adenosine monophosphate, $K^{+}$ potassium ion, $O R$ opioid receptor, $P$ phosphorylation

buprenorphine than by full $\mu$-opioid receptor agonists, this moderate signaling appears sufficient to reach an analgesic threshold while reducing the likelihood of opioid-related adverse side effects that may result from high receptor signaling levels $[12,28,36,38]$. Therefore, despite buprenorphine's partial agonism at the $\mu$-opioid receptor, analgesic efficacy is maintained while the likelihood of respiratory depression and euphoria is decreased and abuse potential is limited by preventing the overstimulation of or excessive signaling from the $\mu$-opioid receptor $[6,11,13,14,23,39-45]$. However, any substance that acts on the $\mu$-opioid receptor or depresses the central nervous system (CNS) could contribute to opioid-related morbidity and mortality $[46,47]$. 
Unfortunately, the classification of buprenorphine as a partial $\mu$-opioid receptor agonist has led to the myth that it produces a weaker analgesic effect than full $\mu$-opioid receptor agonists (e.g., morphine, oxycodone, fentanyl) [8-10]. It is important to note that partial agonism refers to receptor activity level and does not necessarily translate to partial analgesic efficacy [8, 13, 42, 48]. Classifications of receptor activity can vary depending on study conditions, and some in vitro assays have shown morphine to behave as a partial $\mu$-opioid receptor agonist even though it is clinically considered a full agonist $[8,48]$. Depending on the formulation, buprenorphine is approximately 25-115 times more potent as an analgesic than morphine is and should not be considered less potent $[14,49,50]$.

Buprenorphine has shown analgesic efficacy comparable to that of full $\mu$-opioid receptor agonists in moderate to severe post-operative pain and cancer pain, with no demonstrated ceiling effect for analgesia in humans [8]. In fact, the analgesic efficacy observed in clinical trials of two different buprenorphine products FDA approved for the treatment of chronic pain was similar to that of commonly utilized full $\mu$ opioid receptor agonists [51-53].

Tissue specificity also influences drug-induced efficacy, as buprenorphine exhibits unique tissue-specific activity compared with full $\mu$-opioid receptor agonists [13, 54, 55]. In animal studies, spinal injection of naloxone, a $\mu$-opioid receptor antagonist, successfully blocked analgesia caused by buprenorphine, morphine, and fentanyl [55]. Interestingly, supraspinal injection of naloxone blocked the analgesic effects of morphine and fentanyl, but not buprenorphine [55]. These data suggest that buprenorphine exerts its analgesic effects primarily on the lower CNS (spinal cord) rather than the higher CNS (brain) [54-56]. The preferential activity of buprenorphine at spinal opioid receptors promotes analgesia, whereas lack of supraspinal effects may be a contributing factor in limiting adverse events such as euphoria and respiratory depression [27, 55, 57-59] (Fig. 3).

The unique receptor- and tissue-specific activity of buprenorphine, combined with its

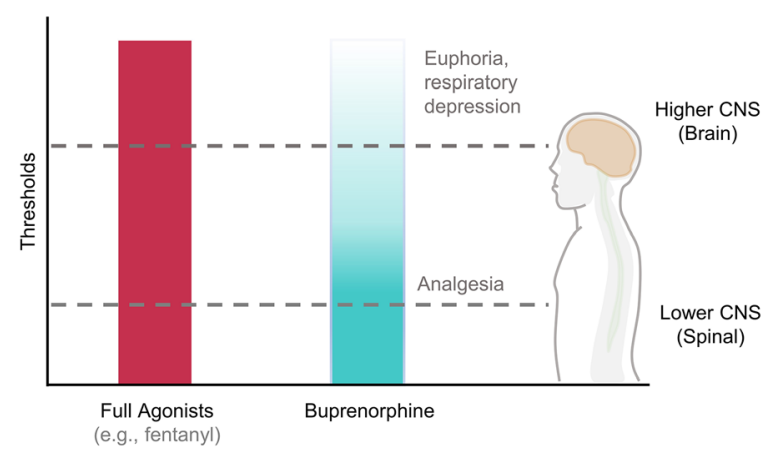

Fig. 3 Buprenorphine activity at spinal $\mu$-opioid receptors provides analgesia while limiting euphoria and respiratory depression. Activation of the $\mu$-opioid receptor results in varying effects depending on the extent of the activation. Full $\mu$-opioid receptor agonists (e.g., fentanyl) promote analgesia but have a high probability of adverse events. As a partial $\mu$-opioid receptor agonist, buprenorphine has receptor activity that sufficiently reaches the analgesic threshold but may demonstrate a ceiling effect on otherwise common opioid-related adverse events. Buprenorphine's partial agonist effects at the $\mu$-opioid receptor and preferential lower CNS activity provide several clinically desirable pharmacological properties compared with full agonists, including less potential for euphoria and respiratory depression in addition to providing equal or superior analgesia $[5,55,59-61]$. CNS central nervous system

unique activation of opioid receptors, produces a range of effects that may be beneficial in chronic pain management. Partial agonism at the $\mu$-opioid receptor, which is specific to buprenorphine, produces potent analgesia $[6,23,41]$ while allowing for a ceiling effect on respiratory depression and euphoria $[39,40,42-44]$ and the reduction of other adverse events commonly observed with opioid use. Antagonism at the $\delta$ - and $\kappa$-opioid receptors limits the potential for adverse effects such as constipation, respiratory depression, anxiety, and addiction, while full agonism of ORL1 contributes to spinal analgesia and may limit the addiction potential and tolerance commonly observed with full $\mu$-opioid receptor agonists [5, 6, 20, 62-69]. Taken together, the unique pharmacodynamics of buprenorphine allow for tolerable, potent analgesia with less physical dependence compared with full $\mu$ - 


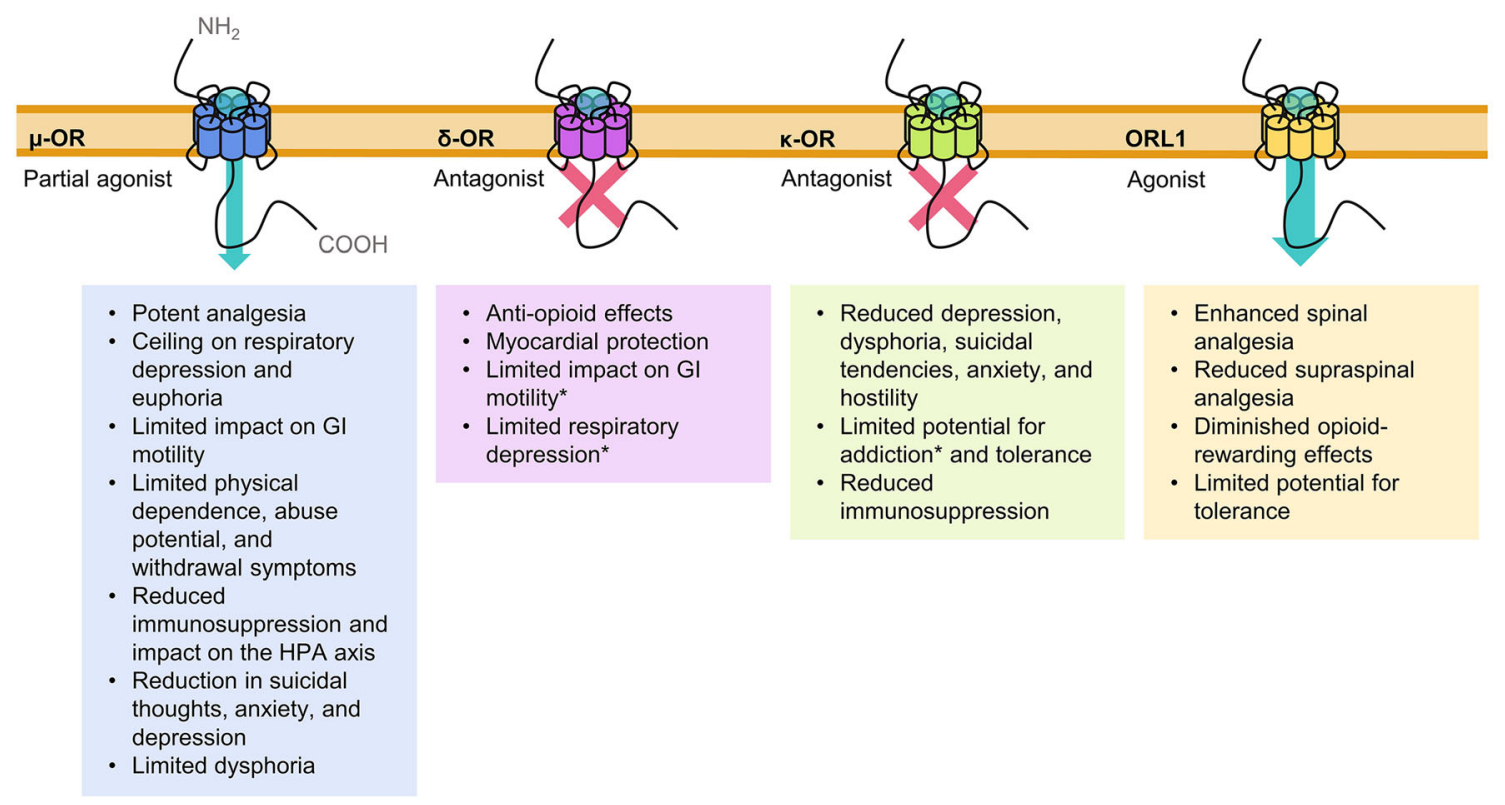

Fig. 4 The unique pharmacodynamics of buprenorphine promote analgesia while potentially reducing adverse effects. The multimechanistic regulation of opioid receptors by buprenorphine results in enhanced analgesia and decreased side effects [72]. Partial agonism at the $\mu$-opioid receptor may result in moderate signaling activity but potent analgesia $[6,23,41]$; a ceiling effect on respiratory depression and euphoria [39, 40, 42-44]; limited impact on GI motility $[69,73]$; limited physical dependence, abuse potential, and withdrawal symptoms [14, 45, 62]; reduced immunosuppression and impact on the HPA axis $[42,69]$; reduction in suicidal thoughts, anxiety, and depression [62]; and limited dysphoria [62]. Antagonism at the $\delta$-opioid receptor may result in anti-opioid action

opioid receptor agonists, reinforcing its utility in the treatment of chronic pain $[6,70-72]$ (Fig. 4).

Clinical studies examining buprenorphine have been performed for various chronic pain types, including chronic low back pain and malignant pain [53, 76-79]. A systematic review of clinical trials that utilized various buprenorphine formulations concluded that $67 \%$ of studies showed buccal buprenorphine film or the transdermal patch significantly reduced pain compared with a comparator [80]. Importantly, no serious adverse events were reported in any of these studies [80]. Thus, clinical data support the preferential pharmacodynamic properties of buprenorphine. However, all
$[67,69]$; myocardial protection [63]; a limited impact on GI motility* [67]; and limited respiratory depression* [67]. Antagonism or inverse agonism [20] at the $\kappa$-opioid receptor may result in reduced depression $[5,66]$, dysphoria [65, 67], suicidal tendencies [62], anxiety [62], and hostility [62]; a limited potential for addiction* and tolerance [5, 20]; and reduced immunosuppression [6]. Full agonism at ORL1 may result in reduced supraspinal analgesia [64, 74]; enhanced spinal analgesia [74]; diminished opioid-rewarding effects $[5,68,75]$; and a limited potential for tolerance [9]. ${ }^{*}$ Predicted effect on the basis of known receptor function. $\mathrm{COOH}$ carboxylic acid, $G I$ gastrointestinal, $H P A$ hypothalamic pituitary adrenal, $O R$ opioid receptor, $O R L 1$ opioid receptor-like 1

opioids, including buprenorphine, can be associated with sleep-disordered breathing [81]. As many patients presenting for chronic pain therapies (and opioid use disorder treatment) are on concomitant CNS depressants, clinicians should be vigilant for the symptoms associated with sleep-disordered breathing and investigate with polysomnography when appropriate.

\section{Pharmacokinetics of Buprenorphine}

The properties of buprenorphine, such as low molecular weight, high lipophilicity, and high potency, contribute to the bioavailability of different formulations (Table 1) [80]. Although 
Table 1 Bioavailability of buprenorphine by formulation

\begin{tabular}{ll}
\hline Route of administration & Bioavailability \\
\hline Intravenous & $100 \%$ \\
Buccal & $46-65 \%$ \\
Sublingual & $28-51 \%$ \\
Transdermal & $15 \%$ \\
\hline
\end{tabular}

Percent bioavailability of the intravenous [82], buccal [83], sublingual $[84,85]$, and transdermal [86] formulations of buprenorphine

buprenorphine is readily absorbed through gastrointestinal and mucosal membranes, the oral absorption of buprenorphine is poor because of first-pass metabolism [87, 88]. Transdermal absorption is also limited; however, formulations have been designed to overcome these obstacles [89]. Administration by the sublingual route is effective, but the buccal formulation is currently the most efficient delivery system that results in the highest observed non-intravenous bioavailability range [82-84].

Following absorption, buprenorphine is largely (96\%) protein bound, primarily to $\alpha$ - and $\beta$ globulin, and exhibits a large volume of distribution, likely due to its high lipophilicity, which may also contribute to its analgesic effects [23, 83, 86-88, 90].

The metabolism of buprenorphine may be through a bioactivation pathway that further contributes to its analgesic effects [91]. The hepatic cytochrome P (CYP) 450 system metabolizes buprenorphine to norbuprenorphine through $\mathrm{N}$-dealkylation of the cyclopropylmethyl group [92-94]. This Ndealkylation step reduces blood-brain barrier transport, as norbuprenorphine does not readily cross the blood-brain barrier $[88,95]$. In vitro studies show that norbuprenorphine exhibits high affinity for the $\mu-, \delta$-, and $\kappa$-opioid receptors and low affinity for ORL1, and preclinical studies confirm its slight contribution to analgesia $[96,97]$. Further structural modification of buprenorphine and norbuprenorphine by UDPglucuronosyl transferase occurs via glucuronidation to create buprenorphine-3- glucuronide and norbuprenorphine-3-glucuronide, respectively [88, 91]. Preclinical evidence suggests that buprenorphine-3glucuronide produces low-potency analgesia, whereas norbuprenorphine-3-glucuronide has a sedative effect [91].

Although both buprenorphine and norbuprenorphine are inhibitors of the metabolic enzymes CYP2D6 and CYP3A4 of the cytochrome P450 system, they are not predicted to cause clinically important interactions with other drugs metabolized by major hepatic P450 enzymes [98, 99]. This translates to fewer drug-drug interactions with buprenorphine compared with other opioids, such as oxycodone or hydrocodone, potentially diminishing adverse events when combining buprenorphine with one or more agents affecting CYP metabolism [43].

Buprenorphine and its metabolites are excreted mainly by the biliary system through enterohepatic recirculation, although a small portion can also be eliminated in feces or urine [100-103]. This mode of excretion makes buprenorphine suitable for patients with renal and hepatic impairment [100, 103, 104]. Because elderly patients are more likely to experience chronic pain and often have renal or hepatic impairment, buprenorphine may be a more suitable choice for this population than full $\mu$-opioid receptor agonists $[5,43]$. In addition, the transdermal and buccal formulations bypass first-pass metabolism, which may be beneficial in patients with concomitant gastrointestinal disease, who are vomiting, or who have difficulty swallowing $[16,105]$.

\section{CONCLUSIONS}

Buprenorphine has unique, multimechanistic pharmacological properties that distinguish it from other opioids. Buprenorphine is considered a partial agonist at the $\mu$-opioid receptor, which describes receptor activity and not its effectiveness as an analgesic. The preferential spinal site of action and partial agonism of buprenorphine at the $\mu$-opioid receptor allow for potent analgesia with potential tolerability and safety advantages. In addition, 
buprenorphine, by DEA definition a Schedule III opioid, is associated with less addiction/ abuse risk than Schedule II full $\mu$-opioid receptor agonists. This is valuable at a time when substance use disorders and drug-related deaths are at an all-time high in our country. There are currently two formulations of buprenorphine available for use in the United States that are indicated for chronic pain management: buprenorphine transdermal patch (Butrans $^{\circledR}$, Purdue Pharma, LP, Stamford, CT) and buprenorphine buccal film (Belbuca ${ }^{\circledR}$, BioDelivery Sciences International, Inc, Raleigh, NC). In summary, the pharmacodynamic and pharmacokinetic properties of buprenorphine, combined with its analgesic properties, potentially favorable safety profile, and potential for use in multiple patient populations, support its effective use in chronic pain management.

\section{ACKNOWLEDGEMENTS}

Funding. This review manuscript and the journal's rapid service publishing charge were funded by BioDelivery Sciences International. Both authors had full access to all of the data in this study and take complete responsibility for the integrity of the data and accuracy of the data analysis.

Medical Writing, Editorial, and Other Assistance. The authors thank Jessica Brunquell, PhD, of MedLogix Communications, LLC, Itasca, Illinois, for medical writing and editorial assistance, which was sponsored by BioDelivery Sciences International.

Authorship. All named authors meet the International Committee of Medical Journal Editors (ICMJE) criteria for authorship for this article, take responsibility for the integrity of the work as a whole, and have given their approval for this version to be published.

Disclosures. In the past year, Jeffrey Gudin has served as a consultant for Averitas, Mallinckrodt, Nektar, and Quest Diagnostics; as an advisory board member for AcelRx
Pharmaceuticals and GlaxoSmithKline; and as a consultant and part of a speakers' bureau for BioDelivery Sciences International, DSI, Salix Pharmaceuticals, and Scilex Pharmaceuticals. Jeffrey Fudin has served as an advisory board member for AcelRx Pharmaceuticals, GlaxoSmithKline, Quest Diagnostics, Scilex Pharmaceuticals, and Salix Pharmaceuticals; as a speaker for Acutis Diagnostics; as part of a speakers' bureau for AstraZeneca; as a consultant for BioDelivery Sciences International and Firstox Laboratories; and as part of an advisory board and speakers' bureau for Daiichi Sankyo.

Compliance with Ethics Guidelines. This article is based on previously conducted studies and does not contain any studies with human participants or animals performed by either of the authors.

Data Availability. Data sharing is not applicable to this article, as no datasets were generated or analyzed during the current study.

Open Access. This article is distributed under the terms of the Creative Commons Attribution-NonCommercial 4.0 International License (http://creativecommons.org/licenses/ by-nc/4.0/), which permits any noncommercial use, distribution, and reproduction in any medium, provided you give appropriate credit to the original author(s) and the source, provide a link to the Creative Commons license, and indicate if changes were made.

\section{REFERENCES}

1. US Health and Human Services. HHS acting secretary declares public health emergency to address national opioid crisis. Available at: https://www. hhs.gov/about/news/2017/10/26/hhs-actingsecretary-declares-public-health-emergencyaddress-national-opioid-crisis.html. Accessed Jan 24, 2019.

2. National Institute on Drug Abuse. Opioid overdose crisis. Updated January 2019. Available at: https:// www.drugabuse.gov/drugs-abuse/opioids/opioidoverdose-crisis. Accessed March 20, 2019. 
3. Substance Abuse and Mental Health Services Administration. Key substance use and mental health indicators in the United States: results from the 2017 national survey on drug use and health (HHS Publication No. SMA 18-5068, NSDUH Series H-53). 2018. Available at: https://www.samhsa.gov/ data/report/2017-nsduh-annual-national-report. Accessed March 20, 2019.

4. US Department of Health and Human Services. Pain management best practices inter-agency task force report: updates, gaps, inconsistencies, and recommendations. 2019. Available at: https://www.hhs. gov/sites/default/files/pmtf-final-report-2019-05-23. pdf. Accessed July 1, 2019.

5. Khanna IK, Pillarisetti S. Buprenorphine-an attractive opioid with underutilized potential in treatment of chronic pain. J Pain Res. 2015;8: 859-70.

6. Kress HG. Clinical update on the pharmacology, efficacy and safety of transdermal buprenorphine. Eur J Pain. 2009;13(3):219-30.

7. Lewis JW. Ring C-bridged derivatives of thebaine and oripavine. Adv Biochem Psychopharmacol. 1973;8:123-36.

8. Raffa RB, Haidery M, Huang HM, Kalladeen K, Lockstein DE, Ono $\mathrm{H}$, et al. The clinical analgesic efficacy of buprenorphine. J Clin Pharm Ther. 2014;39(6):577-83.

9. Harald B. Buprenorphine-the ideal drug for most clinical indications for an opioid? Scand J Pain. 2013;4(3):146-7.

10. Butler S. Buprenorphine-clinically useful but often misunderstood. Scand J Pain. 2013;4(3):148-52.

11. Ehrlich AT, Darcq E. Recommending buprenorphine for pain management. Pain Manag. 2019;9(1):13-6.

12. Corder G, Castro DC, Bruchas MR, Scherrer G. Endogenous and exogenous opioids in pain. Annu Rev Neurosci. 2018;41:453-73.

13. Berg KA, Clarke WP. Making sense of pharmacology: inverse agonism and functional selectivity. Int J Neuropsychopharmacol. 2018;21(10):962-77.

14. Jasinski DR, Pevnick JS, Griffith JD. Human pharmacology and abuse potential of the analgesic buprenorphine: a potential agent for treating narcotic addiction. Arch Gen Psychiatry. 1978;35(4): 501-16.

15. The National Alliance of Advocates for Buprenorphine Treatment. Buprenorphine: a treatment for opioid addiction in the privacy of a doctor's office.
2015. Available at: http://www.naabt.org/ documents/naabt_brochure\%20Version\%202.pdf. Accessed March 25, 2019.

16. Davis MP, Pasternak G, Behm B. Treating chronic pain: an overview of clinical studies centered on the buprenorphine option. Drugs. 2018;78(12): 1211-28.

17. Sutcliffe KJ, Henderson G, Kelly E, Sessions RB. Drug binding poses relate structure with efficacy in the mu opioid receptor. J Mol Biol. 2017;429(12): 1840-51.

18. Volpe DA, McMahon Tobin GA, Mellon RD, Katki AG, Parker RJ, Colatsky T, et al. Uniform assessment and ranking of opioid mu receptor binding constants for selected opioid drugs. Regul Toxicol Pharmacol. 2011;59(3):385-90.

19. Khroyan TV, Wu J, Polgar WE, Cami-Kobeci G, Fotaki N, Husbands SM, et al. BU08073 a buprenorphine analogue with partial agonist activity at mu-receptors in vitro but long-lasting opioid antagonist activity in vivo in mice. Br J Pharmacol. 2015;172(2):668-80.

20. Grinnell SG, Ansonoff M, Marrone GF, Lu Z, Narayan $\mathrm{A}, \mathrm{Xu} \mathrm{J}$, et al. Mediation of buprenorphine analgesia by a combination of traditional and truncated mu opioid receptor splice variants. Synapse. 2016;70(10):395-407.

21. Zuurmond WW, Meert TF, Noorduin H. Partial versus full agonists for opioid-mediated analgesia-focus on fentanyl and buprenorphine. Acta Anaesthesiol Belg. 2002;53(3):193-201.

22. Matthes HW, Maldonado R, Simonin F, Valverde O, Slowe S, Kitchen I, et al. Loss of morphine-induced analgesia, reward effect and withdrawal symptoms in mice lacking the mu-opioid-receptor gene. Nature. 1996;383(6603):819-23.

23. Yassen A, Olofsen E, Romberg R, Sarton E, Danhof M, Dahan A. Mechanism-based pharmacokineticpharmacodynamic modeling of the antinociceptive effect of buprenorphine in healthy volunteers. Anesthesiology. 2006;104(6):1232-42.

24. Larochelle MR, Bernson D, Land T, Stopka TJ, Wang $\mathrm{N}$, Xuan Z, et al. Medication for opioid use disorder after nonfatal opioid overdose and association with mortality: a cohort study. Ann Intern Med. 2018;169(3):137-45.

25. Troster A, Ihmsen H, Singler B, Filitz J, Koppert W. Interaction of fentanyl and buprenorphine in an experimental model of pain and central sensitization in human volunteers. Clin J Pain. 2012;28(8): 705-11. 
26. Boas RA, Villiger JW. Clinical actions of fentanyl and buprenorphine. The significance of receptor binding. Br J Anaesth. 1985;57(2):192-6.

27. Pathan H, Williams J. Basic opioid pharmacology: an update. Br J Pain. 2012;6(1):11-6.

28. Just S, Illing S, Trester-Zedlitz M, Lau EK, Kotowski SJ, Miess E, et al. Differentiation of opioid drug effects by hierarchical multi-site phosphorylation. Mol Pharmacol. 2013;83(3):633-9.

29. Schmid CL, Kennedy NM, Ross NC, Lovell KM, Yue $\mathrm{Z}$, Morgenweck J, et al. Bias factor and therapeutic window correlate to predict safer opioid analgesics. Cell. 2017;171(5):1165-75 e13.

30. Cahill CM, Walwyn W, Taylor AMW, Pradhan AAA, Evans CJ. Allostatic mechanisms of opioid tolerance beyond desensitization and downregulation. Trends Pharmacol Sci. 2016;37(11):963-76.

31. Whistler JL, Chuang HH, Chu P, Jan LY, von Zastrow M. Functional dissociation of $\mathrm{mu}$ opioid receptor signaling and endocytosis: implications for the biology of opiate tolerance and addiction. Neuron. 1999;23(4):737-46.

32. Lau EK, Trester-Zedlitz M, Trinidad JC, Kotowski SJ, Krutchinsky AN, Burlingame AL, et al. Quantitative encoding of the effect of a partial agonist on individual opioid receptors by multisite phosphorylation and threshold detection. Sci Signal. 2011;4(185):ra52.

33. Raehal KM, Bohn LM. The role of beta-arrestin2 in the severity of antinociceptive tolerance and physical dependence induced by different opioid pain therapeutics. Neuropharmacology. 2011;60(1): $58-65$.

34. Luttrell LM, Maudsley S, Bohn LM. Fulfilling the promise of "biased" G protein-coupled receptor agonism. Mol Pharmacol. 2015;88(3):579-88.

35. Kenakin T. Functional selectivity through protean and biased agonism: who steers the ship? Mol Pharmacol. 2007;72(6):1393-401.

36. McPherson J, Rivero G, Baptist M, Llorente J, AlSabah S, Krasel C, et al. mu-Opioid receptors: correlation of agonist efficacy for signalling with ability to activate internalization. Mol Pharmacol. 2010;78(4):756-66.

37. Schulz S, Mayer D, Pfeiffer M, Stumm R, Koch T, Hollt V. Morphine induces terminal micro-opioid receptor desensitization by sustained phosphorylation of serine-375. EMBO J. 2004;23(16):3282-9.

38. Saidak Z, Blake-Palmer K, Hay DL, Northup JK, Glass M. Differential activation of G-proteins by mu- opioid receptor agonists. $\mathrm{Br} \mathrm{J}$ Pharmacol. 2006;147(6):671-80.

39. Dahan A, Yassen A, Romberg R, Sarton E, Teppema L, Olofsen E, et al. Buprenorphine induces ceiling in respiratory depression but not in analgesia. Br J Anaesth. 2006;96(5):627-32.

40. Dahan A, Yassen A, Bijl H, Romberg R, Sarton E, Teppema L, et al. Comparison of the respiratory effects of intravenous buprenorphine and fentanyl in humans and rats. $\mathrm{Br} \mathrm{J}$ Anaesth. 2005;94(6): 825-34.

41. Cowan A, Lewis JW, Macfarlane IR. Agonist and antagonist properties of buprenorphine, a new antinociceptive agent. Br J Pharmacol. 1977;60(4): $537-45$.

42. Pergolizzi J, Aloisi AM, Dahan A, Filitz J, Langford R, Likar R, et al. Current knowledge of buprenorphine and its unique pharmacological profile. Pain Pract. 2010;10(5):428-50.

43. Pergolizzi J, Boger RH, Budd K, Dahan A, Erdine S, Hans G, et al. Opioids and the management of chronic severe pain in the elderly: consensus statement of an international expert panel with focus on the six clinically most often used World Health Organization Step III opioids (buprenorphine, fentanyl, hydromorphone, methadone, morphine, oxycodone). Pain Pract. 2008;8(4):287-313.

44. Walsh SL, Preston KL, Bigelow GE, Stitzer ML. Acute administration of buprenorphine in humans: partial agonist and blockade effects. J Pharmacol Exp Ther. 1995;274(1):361-72.

45. Zubieta J, Greenwald MK, Lombardi U, Woods JH, Kilbourn MR, Jewett DM, et al. Buprenorphine-induced changes in mu-opioid receptor availability in male heroin-dependent volunteers: a preliminary study. Neuropsychopharmacology. 2000;23(3): 326-34.

46. Schiller EY, Mechanic OJ. Opioid Overdose. StatPearls. Treasure Island (FL) 2019.

47. Pattinson KT. Opioids and the control of respiration. Br J Anaesth. 2008;100(6):747-58.

48. Traynor J. mu-Opioid receptors and regulators of G protein signaling (RGS) proteins: from a symposium on new concepts in mu-opioid pharmacology. Drug Alcohol Depend. 2012;121(3):173-80.

49. Sittl R, Likar R, Nautrup BP. Equipotent doses of transdermal fentanyl and transdermal buprenorphine in patients with cancer and noncancer pain: results of a retrospective cohort study. Clin Ther. $2005 ; 27(2): 225-37$. 
50. Foster B, Twycross R, Mihalyo M, Wilcock A. Buprenorphine. J Pain Symptom Manag. 2013;45(5):939-49.

51. Meske DS, Lawal OD, Elder H, Langberg V, Paillard F, Katz N. Efficacy of opioids versus placebo in chronic pain: a systematic review and meta-analysis of enriched enrollment randomized withdrawal trials. J Pain Res. 2018;11:923-34.

52. Steiner D, Munera C, Hale M, Ripa S, Landau C. Efficacy and safety of buprenorphine transdermal system (BTDS) for chronic moderate to severe low back pain: a randomized, double-blind study. J Pain. 2011;12(11):1163-73.

53. Rauck RL, Potts J, Xiang Q, Tzanis E, Finn A. Efficacy and tolerability of buccal buprenorphine in opioidnaive patients with moderate to severe chronic low back pain. Postgrad Med. 2016;128(1):1-11.

54. Tejwani GA, Rattan AK. The role of spinal opioid receptors in antinociceptive effects produced by intrathecal administration of hydromorphone and buprenorphine in the rat. Anesth Analg. 2002;94(6):1542-6.

55. Ding Z, Raffa RB. Identification of an additional supraspinal component to the analgesic mechanism of action of buprenorphine. $\mathrm{Br} \mathrm{J}$ Pharmacol. 2009;157(5):831-43.

56. Gerhold KJ, Drdla-Schutting R, Honsek SD, Forsthuber L, Sandkuhler J. Pronociceptive and antinociceptive effects of buprenorphine in the spinal cord dorsal horn cover a dose range of four orders of magnitude. J Neurosci. 2015;35(26): 9580-94.

57. Dahan A, van der Schrier R, Smith T, Aarts L, van Velzen M, Niesters M. Averting opioid-induced respiratory depression without affecting analgesia. Anesthesiology. 2018;128(5):1027-37.

58. Schaefer CP, Tome ME, Davis TP. The opioid epidemic: a central role for the blood brain barrier in opioid analgesia and abuse. Fluids Barriers CNS. 2017;14(1):32.

59. Buprenorphine thresholds (euphoria, respiratory depression, and analgesia) and activities location (brain v spinal). Available at: https://paindr.com/ wp-content/uploads/2019/08/Figure-3.tif. Accessed Oct 16, 2019.

60. US Department of Health and Human Services: Substance Abuse and Mental Health Service Administration. Clinical guidelines for the use of buprenorphine in the treatment of opioid addiction. DHHS Publication No. (SMA) 04-3939. Rockville, MD: Substance Abuse and Mental Health Services Administration; 2004.
61. The National Alliance of Advocates for Buprenorphine Treatment. Thorough technical explanation of buprenorphine. Available at: https://www.naabt. org/education/technical_explanation buprenorphine.cfm. Accessed April 8, 2019.

62. Ahmadi J, Jahromi MS, Ehsaei Z. The effectiveness of different singly administered high doses of buprenorphine in reducing suicidal ideation in acutely depressed people with co-morbid opiate dependence: a randomized, double-blind, clinical trial. Trials. 2018;19(1):462.

63. Benedict PE, Benedict MB, Su TP, Bolling SF. Opiate drugs and delta-receptor-mediated myocardial protection. Circulation. 1999;100(19 Suppl):II357-60.

64. Lutfy K, Eitan S, Bryant CD, Yang YC, Saliminejad $\mathrm{N}$, Walwyn $\mathrm{W}$, et al. Buprenorphine-induced antinociception is mediated by mu-opioid receptors and compromised by concomitant activation of opioid receptor-like receptors. J Neurosci. 2003;23(32):10331-7.

65. Robinson SE. Buprenorphine: an analgesic with an expanding role in the treatment of opioid addiction. CNS Drug Rev. 2002;8(4):377-90.

66. Rothman RB, Gorelick DA, Heishman SJ, Eichmiller PR, Hill BH, Norbeck J, et al. An open-label study of a functional opioid kappa antagonist in the treatment of opioid dependence. J Subst Abuse Treat. 2000;18(3):277-81.

67. Stein C, Machelska H. Modulation of peripheral sensory neurons by the immune system: implications for pain therapy. Pharmacol Rev. 2011;63(4): 860-81.

68. Zaveri NT. The nociceptin/orphanin FQ receptor (NOP) as a target for drug abuse medications. Curr Top Med Chem. 2011;11(9):1151-6.

69. Likar R. Transdermal buprenorphine in the management of persistent pain-safety aspects. Ther Clin Risk Manag. 2006;2(1):115-25.

70. Drug Enforcement Administration Diversion Control Division. Rescheduling of buprenorphine from Schedule V to Schedule III. 2002. Available at: https://www.deadiversion.usdoj.gov/fed_regs/rules/ 2002/fr1007.htm. Accessed March 20, 2019.

71. Johnson RE, McCagh JC. Buprenorphine and naloxone for heroin dependence. Curr Psychiatry Rep. 2000;2(6):519-26.

72. Opioid receptor delineation and activities. Available at: https://paindr.com/wp-content/uploads/2019/ 08/Figure-4.tif. Accessed Oct 16, 2019. 
73. Griessinger N, Sittl R, Likar R. Transdermal buprenorphine in clinical practice-a post-marketing surveillance study in 13,179 patients. Curr Med Res Opin. 2005;21(8):1147-56.

74. Davis MP. Twelve reasons for considering buprenorphine as a frontline analgesic in the management of pain. J Support Oncol. 2012;10(6): 209-19.

75. Marquez P, Borse J, Nguyen AT, Hamid A, Lutfy K. The role of the opioid receptor-like (ORL1) receptor in motor stimulatory and rewarding actions of buprenorphine and morphine. Neuroscience. 2008;155(3):597-602.

76. Gimbel J, Spierings EL, Katz N, Xiang Q, Tzanis E, Finn A. Efficacy and tolerability of buccal buprenorphine in opioid-experienced patients with moderate to severe chronic low back pain: results of a phase 3, enriched enrollment, randomized withdrawal study. Pain. 2016;157(11):2517-26.

77. Hale M, Urdaneta V, Kirby MT, Xiang Q, Rauck R. Long-term safety and analgesic efficacy of buprenorphine buccal film in patients with moderate-to-severe chronic pain requiring around-theclock opioids. J Pain Res. 2017;10:233-40.

78. Pace MC, Passavanti MB, Grella E, Mazzariello L, Maisto M, Barbarisi M, et al. Buprenorphine in longterm control of chronic pain in cancer patients. Front Biosci. 2007;12:1291-9.

79. Poulain P, Denier W, Douma J, Hoerauf K, Samija M, Sopata M, et al. Efficacy and safety of transdermal buprenorphine: a randomized, placebo-controlled trial in 289 patients with severe cancer pain. J Pain Symptom Manag. 2008;36(2):117-25.

80. Aiyer R, Gulati A, Gungor S, Bhatia A, Mehta N. Treatment of chronic pain with various buprenorphine formulations: a systematic review of clinical studies. Anesth Analg. 2018;127(2):529-38.

81. DeVido J, Connery H, Hill KP. Sleep-disordered breathing in patients with opioid use disorders in long-term maintenance on buprenorphine-naloxone: a case series. J Opioid Manag. 2015;11(4): 363-6.

82. Huestis MA, Cone EJ, Pirnay SO, Umbricht A, Preston KL. Intravenous buprenorphine and norbuprenorphine pharmacokinetics in humans. Drug Alcohol Depend. 2013;131(3):258-62.

83. Belbuca ${ }^{\circledR}$ (buprenorphine buccal film) [prescribing information]. Raleigh, NC: BioDelivery Sciences International, Inc.; 2018.

84. Kuhlman JJ Jr, Lalani S, Magluilo J Jr, Levine B, Darwin WD. Human pharmacokinetics of intravenous, sublingual, and buccal buprenorphine. J Anal Toxicol. 1996;20(6):369-78.

85. Mendelson J, Upton RA, Everhart ET, Jacob P 3rd, Jones RT. Bioavailability of sublingual buprenorphine. J Clin Pharmacol. 1997;37(1):31-7.

86. Butrans ${ }^{\circledR}$ (buprenorphine transdermal system) [prescribing information]. Stamford, CT: Purdue Pharma L.P.; 2018.

87. Elkader A, Sproule B. Buprenorphine: clinical pharmacokinetics in the treatment of opioid dependence. Clin Pharmacokinet. 2005;44(7):661-80.

88. Marquet P. Pharmacology of high dose buprenorphine. In: Kintz P, Marquet P, editors. Buprenorphine Therapy of Opiate Addiction. Totowa (NJ): Humana Press; 2002. p. 1-11.

89. Stinchcomb AL, Paliwal A, Dua R, Imoto H, Woodard RW, Flynn GL. Permeation of buprenorphine and its 3-alkyl-ester prodrugs through human skin. Pharm Res. 1996;13(10):1519-23.

90. Probuphine [prescribing information]. South San Francisco, CA. Titran Pharmaceuticals, Inc; 2018.

91. Brown SM, Holtzman M, Kim T, Kharasch ED. Buprenorphine metabolites, buprenorphine-3-glucuronide and norbuprenorphine-3-glucuronide, are biologically active. Anesthesiology. 2011;115(6): 1251-60.

92. Kobayashi K, Yamamoto T, Chiba K, Tani M, Shimada N, Ishizaki T, et al. Human buprenorphine $\mathrm{N}$-dealkylation is catalyzed by cytochrome $\mathrm{P} 450$ 3A4. Drug Metab Dispos. 1998;26(8):818-21.

93. Moody DE, Slawson MH, Strain EC, Laycock JD, Spanbauer AC, Foltz RL. A liquid chromatographicelectrospray ionization-tandem mass spectrometric method for determination of buprenorphine, its metabolite, norbuprenorphine, and a coformulant, naloxone, that is suitable for in vivo and in vitro metabolism studies. Anal Biochem. 2002;306(1): 31-9.

94. Picard N, Cresteil T, Djebli N, Marquet P. In vitro metabolism study of buprenorphine: evidence for new metabolic pathways. Drug Metab Dispos. 2005;33(5):689-95.

95. Brown SM, Campbell SD, Crafford A, Regina KJ, Holtzman MJ, Kharasch ED. P-glycoprotein is a major determinant of norbuprenorphine brain exposure and antinociception. J Pharmacol Exp Ther. 2012;343(1):53-61.

96. Huang P, Kehner GB, Cowan A, Liu-Chen LY. Comparison of pharmacological activities of buprenorphine and norbuprenorphine: 
norbuprenorphine is a potent opioid agonist. J Pharmacol Exp Ther. 2001;297(2):688-95.

97. Ohtani M, Kotaki H, Sawada Y, Iga T. Comparative analysis of buprenorphine- and norbuprenorphineinduced analgesic effects based on pharmacokinetic-pharmacodynamic modeling. J Pharmacol Exp Ther. 1995;272(2):505-10.

98. Umehara K, Shimokawa Y, Miyamoto G. Inhibition of human drug metabolizing cytochrome $\mathrm{P} 450$ by buprenorphine. Biol Pharm Bull. 2002;25(5):682-5.

99. Zhang W, Ramamoorthy Y, Tyndale RF, Sellers EM. Interaction of buprenorphine and its metabolite norbuprenorphine with cytochromes p450 in vitro. Drug Metab Dispos. 2003;31(6):768-72.

100. Brewster D, Humphrey MJ, McLeavy MA. Biliary excretion, metabolism and enterohepatic circulation of buprenorphine. Xenobiotica. 1981;11(3): 189-96.

101. Cone EJ, Gorodetzky CW, Yousefnejad D, Buchwald WF, Johnson RE. The metabolism and excretion of buprenorphine in humans. Drug Metab Dispos. 1984;12(5):577-81.

102. Blom Y, Bondesson U, Anggard E. Analysis of buprenorphine and its N-dealkylated metabolite in plasma and urine by selected-ion monitoring. J Chromatogr. 1985;338(1):89-98.

103. Heel RC, Brogden RN, Speight TM, Avery GS. Buprenorphine: a review of its pharmacological properties and therapeutic efficacy. Drugs. 1979;17(2):81-110.

104. Filitz J, Griessinger N, Sittl R, Likar R, Schuttler J, Koppert W. Effects of intermittent hemodialysis on buprenorphine and norbuprenorphine plasma concentrations in chronic pain patients treated with transdermal buprenorphine. Eur J Pain. 2006;10(8):743-8.

105. Gordon A, Callaghan D, Spink D, Cloutier C, Dzongowski P, O'Mahony W, et al. Buprenorphine transdermal system in adults with chronic low back pain: a randomized, double-blind, placebo-controlled crossover study, followed by an open-label extension phase. Clin Ther. 2010;32(5):844-60. 